Vol.3 No.2 Hal. 51- 56

September 2020
BEST JOURNAL

(Biology Education,Science \& Technolog̉y)

Fakultas Keguruan dan IImu Pendidikan
ISSN (Print) : $2614-8064$

ISSN (Online): $2654-4652$

\title{
Analisis Kemampuan Literasi Membaca Siswa Sekolah Dasar di Kota Langsa
}

\author{
Allif Syahputra Bania ${ }^{(1)}, \operatorname{Imran}^{(2)}$ \\ Pendidikan Bahasa Inggris Fakultas Keguruan dan Ilmu Pendidikan \\ Universitas Samudra ${ }^{(1)(2)}$ \\ allifbania@unsam.ac.id ${ }^{(1)}$,imran@unsam.ac.id ${ }^{(2)}$
}

\begin{abstract}
ABSTRAK
Tujuan penelitian adalah Untuk mendeskripsikan kemampuan literasi membaca bahasa Aceh berbasis teks pada mata pelajaran muatan lokal bahasa Aceh di SD 10 Kota Langsa. Sampel disesuaikan dengan keadaan new normal dimana siswa dipilih sebanyak 15 orang siswa yang mudah dijumpai dan diberikan izin oleh wali siswa untuk menjadi objek penelitian serta dilaksanakan dengan menjalankan protokol kesehatan. Selanjutnya Teknik pengumpulan data dilakukan dengan penelitian langsung yaitu: Observasi, memberikan tes dan menganalisis data hasil tes untuk menentukan tingkat kemampuan literasi membaca bahasa Aceh.
\end{abstract}

Kata Kunci : Literasi, Membaca, Siswa

\begin{abstract}
The purpose of this study is to describe literacy skills in reading Acehnese language based on text in Elementary School Number 10 , Langsa City. The sample was adjusted to the new normal situation where 15 students were selected, which were easily found and given permission by the student's guardian to be the object of research and carried out by implementing the health protocol. Furthermore, data collection techniques were carried out with direct research, namely: Observation, giving tests and analyzing test result data to determine the level of literacy skills in Acehnese language.
\end{abstract}

Keywords : Literacy, Reading, Students 


\section{PENDAHULUAN}

\section{Latar Belakang}

Setiap bangsa di dunia sedang menghadapi tantangan globalisasi. Demikian pula dengan Negara Kesatuan Republik Indonesia dengan keberagaman yang dimilikinya harus mampu mempertahankan adat dan budaya bangsa. Salah satu aset yang harus dipertahankan adalah bahasa daerah. Ancaman menurun dan hilangnya penggunaan bahasa daerah biasanya terjadi di daerah dengan tingkat multikulturisme yang tinggi. Di Provinsi Aceh, kota Langsa merupakan salah satu kota madya dengan penduduk yang sangat heterogen. Kebhinnekaan latar belakang masyarakat kota Langsa terjaga dalam kaidah tenggang rasa, gotong royong dan nasionalisme yang erat. Keeratan pembauran masyarakat yang beragam ini tidak pernah lepas dari kegiatan berkomunikasi sebagai salah satu syarat terbinanya kehidupan bermasyarakat sebagai makhluk sosial. Bahasa Indonesia adalah bahasa yang mempersatukan antar suku sebagai bahasa pengantar komunikasi, termasuk juga dalam kegiatan belajar dan mengajar di sekolah. Penggunaan bahasa daerah di sekolah hanya terbatas bagi kalangan penutur bahasa Aceh sedangkan siswa sekolah di langsa kebanyakan berasal dari suku yang beraneka ragam. Data Badan Pusat Statistik tahun 2016, penduduk kota Langsa berjumlah 168.820 jiwa. Keragaman suku yang ada di kota Langsa diantaranya suku Aceh, suku Jawa, suku Minang dan etnis Cina. Adanya banyak bahasa yang bersanding di Kota Langsa dengan penduduk multikultural maka bisa menyebabkan banyak bahasa tersebut hidup berdampingan secara seimbang dan setara atau bahkan menyebabkan salah satu bahasa menjadi dominan sehingga ditakutkan ada bahasa yang beresiko mengalami kepunahan. Keberhasilan mempertahankan kemampuan literasi bahasa daerah terutama bahasa Aceh di Langsa harus ditujukan sedini mungkin kepada siswa sekolah dasar. Fenomena saat ini, banyak siswa yang berasal dari suku Aceh di Langsa yang lancar berbahasa persatuan yakni bahasa Indonesia dan sebaliknya kurang berbakat untuk menutur bahasa Aceh walaupun mereka berasal dari keluarga penutur bahasa Aceh. Penyebab kurangnya kemampuan literasi anak yang berasal dari keluarga penutur bahasa Aceh ini disebabkan kurangnya pemberian stimulasi atau rangsangan oleh orang tua dan metode pembelajaran yang kurang memperhatikan karakteristik siswa. Kegiatan mempertahankan bahasa daerah bersifat urgensi, dalam pendidikan sekolah dasar sangat penting penekanan untuk melestarikan bahasa nasional dan bahasa daerah sebagai bahasa ibu karena sebagai khazanah budaya di Nusantara. Oleh sebab itu, Kemampuan literasi berbahasa Aceh harus dibina dengan baik pada sekolah dasar di Kota Langsa agar bahasa daerah dapat bertahan dari tantangan globalisasi sekalipun. Berdasarkan hasil observasi kami sebagai peneliti ke sekolah dasar yang ada di Kota Langsa Provinsi Aceh, yang mewawancari Kepala Sekolah dan guru SD 10 Kota Langsa yaitu permasalahan kemampuan literasi berbahasa Aceh berbasis teks yang masih sulit untuk diterapkan kepada siswa karena metode pengajaran yang belum bisa mengklasifikasi karakter setiap siswa, kurangnya akses belajar dan mengajar berkenaan dengan teks berbahasa Aceh dan kemampuan membaca bahasa Aceh yang belum distimulasi secara terarah.

\section{Perumusan Masalah}

Suatu kewajaran menganggap membaca sebagai bagian literasi yang merupakan keterampilan yang berkembang secara terus-menerus menjadi suatu praktek sosial yang tidak berbeda dengan keterampilan kognitif, oleh karena itu arti penting dari disiplin literasi dapat dianggap sebagai serangkaian praktek sosial yang berbasis sekolah. Kemampuan literasi membaca siswa juga tidak lepas dari persiapan guru dalam proses persiapan mengajar membaca karena guru memiliki akses yang dekat dan cukup waktu bersama siswa. 


\section{Tujuan Penelitian}

Menjadikan guru menjadi mampu untuk memberikan stimulasi untuk merangsang kemampuan literasi membaca teks berbahasa Aceh oleh Siswa secara maksimal serta Metode pembelajaran belum dapat mengklasifikasi karakter masing-masing siswa sesuai minat untuk mensukseskan peningkatan kemampuan literasi membaca bahasa Aceh yang berbasis teks

\section{Manfaat Penelitian}

Manfaat yang akan didapat dari penelitian ini adalah mendapatkan hasil literasi membaca memiliki fungsi untuk meningkatkan pemikiran kritis dan kemampuan pemahaman membaca yang sangat bermanfaat dalam berbagai aspek pembelajaran. Bagaimanapun, literasi membaca yang menyenangkan tidak boleh berhenti sekedar sebagai kegiatan siswa di ruang kelas karena manfaat dari kemampuan literasi membaca akan sangat berguna kelak ketika siswa menjadi dewasa serta terjun ke dunia kerja dan sosial.

\section{METODE PENELITIAN}

Penelitian ini menggunakan metode tes dengan pendekatan deskriptif kuantitatif. Penelitian ini bertujuan untuk menganalisis dan mendeskripsikan fakta berupa kemampuan literasi membaca oleh siswa SD 10 di Kota Langsa. Metode tes digunakan untuk mengumpulkan data kemampuan literasi membaca dalam pembelajaran muatan lokal Bahasa Aceh. Soal diambil dari teks berbahasa Aceh yang berupa dialog dengan judul " DISIPLIN LAM UDÉP" yang termaktub dalam buku 'Peulajaran Basa Aceh' dari Pustaka Majelis Adat Aceh dengan jumlah 5 butir soal.

\section{Teknik Analisa Data}

Teknik analisa data dalam penelitian ini adalah deskriptif kuantitatif yang menggunakan tiga alur kegiatan penelitian yaitu Reduksi Data (data reduction), Penyajian Data (data display), dan Penarikan Kesimpulan atau Verifikasi (conclusion drawing/verification).

\section{HASIL DAN PEMBAHASAN}

\section{Hasil Penelitian}

Hasil analisis kemampuan literasi membaca berbahasa Aceh yang diadakan pada SD Negeri 10 Langsa dengan jumlah 15 siswa sebagai sampel acak yang sudah dilaksanakan menurut protokol kesehatan pada masa new normal dan mendapatkan izin dari wali murid dapat dilihat pada tabel dibawah ini.

Tabel 1. Hasil Tes Kemampuan Literasi Membaca Berbahasa Aceh Oleh Siswa

\begin{tabular}{|l|l|l|}
\hline Soal & Banyak Siswa (dari 15 sampel acak) \\
\cline { 2 - 3 } & Mampu & Tidak Mampu \\
\hline $\begin{array}{l}\text { 1. Peu nyang jeut tacok } \\
\text { meunafaat lam teks nyan } \\
\text { ban lheueh tadeungo? }\end{array}$ & 6 Siswa & 9 Siswa \\
\hline $\begin{array}{l}\text { 2. Peu nyang geukheun } \\
\text { deungon disiplin? }\end{array}$ & 11 Siswa & 4 Siswa \\
\hline $\begin{array}{l}\text { 3. Pakon mantong na } \\
\text { ureueng nyang geulangga } \\
\text { disiplin? }\end{array}$ & 11 Siswa & 4 Siswa \\
\hline $\begin{array}{l}\text { 4. Peue keundalajih dalam } \\
\text { tapeukong disiplin? }\end{array}$ & 11 Siswa & 4 Siswa \\
\hline
\end{tabular}




\begin{tabular}{|l|l|l|}
\hline $\begin{array}{l}\text { 5. Pakiban peundapat gata } \\
\text { keu ureung nyang kayem } \\
\text { geulangga disiplin? }\end{array}$ & 8 Siswa \\
\hline
\end{tabular}

Dari hasil tes menggambarkan bahwasanya ada variasi jumlah siswa yang mampu atau tidak mampu menjawab soal yang disajikan. Pada soal nomor 1, terdapat perbedaan yang hampir mencolok antara siswa yang mampu memahami literasi membaca teks berbahasa Aceh dengan yang tidak mampu dimana sebanyak $40 \%$ atau 6 siswa mampu memahami soal dan $60 \%$ atau 9 siswa tidak mampu memahami soal. Begitu pula, soal nomor 5 dimana hanya 46,6\% atau 7 Siswa mampu memahami soal sedangkan 53,3\% atau 8 Siswa tidak mampu memahami soal untuk menjawab. Kemudian, Pada soal nomor 2, 3, dan 4 terdapat hasil skor kemampuan memahami soal dengan jumlah siswa yang sama yakni 73,3\% atau 11 Siswa, begitu pula dengan jumlah siswa yang tidak mampu memahami soal untuk menjawab teks berbahasa Aceh dari ketiga nomor tersebut sejumlah 26,6\% atau 4 siswa.

Berikut ditampilkan hasil yang diperoleh dari tabel analisis kemampuan literasi membaca siswa terhadap 5 soal yang disadur dari teks bacaan berbahasa Aceh dimana ternyata ke- 5 soal tersebut dapat dibagi kedalam 2 jenis soal yang mengharuskan kemampuan literasi membaca siswa dipadukan kedalam 2 kategori penalaran soal yaitu yang pertama adalah soal yang berupa pertanyaan bernalar bebas dimana siswa diminta untuk mampu mengutarakan jawaban berupa opini atau pernyataan yang diungkapkan tanpa adanya bantuan jawaban yang jelas atau konkrit yang tersurat didalam dialog yaitu soal nomor 1 dan soal nomor 5 sedangkan jenis soal lainnya berupa pertanyaan berkenaan dengan teks berbahan baca bahasa Aceh dimana secara tersurat sudah jelas ada jawaban yang padu dan terikat terhadap soal yang ditanyakan yaitu soal nomor 2, 3 dan 4 .

Tabel 2. Hasil Analisis Kemampuan Literasi Membaca Teks Berbahasa Aceh

\begin{tabular}{|c|c|c|c|c|}
\hline \multirow[b]{2}{*}{ Soal } & \multicolumn{2}{|l|}{ Jenis Soal } & \multirow[b]{2}{*}{$\begin{array}{l}\text { Hasil Tes } \\
\text { Berdasarkan } \\
\text { Jumlah Siswa }\end{array}$} & \multirow{2}{*}{$\begin{array}{l}\text { Kemampuan } \\
\text { Literasi } \\
\text { Membaca Teks } \\
\text { Berbahasa Aceh } \\
\text { oleh Siswa }\end{array}$} \\
\hline & $\begin{array}{l}\text { Soal Jawaban } \\
\text { Tersurat }\end{array}$ & $\begin{array}{l}\text { Soal Jawaban } \\
\text { Tersirat }\end{array}$ & & \\
\hline $\begin{array}{l}\text { 1. Peu nyang } \\
\text { jeut tacok } \\
\text { meunafaat lam } \\
\text { teks nyan ban } \\
\text { lheueh } \\
\text { tadeungo? }\end{array}$ & $X$ & $\sqrt{ }$ & $\begin{array}{ll}6 & \text { Siswa } \\
\text { Mampu; } & \\
9 \text { Siswa } & \text { Tidak } \\
\text { Mampu } & \end{array}$ & $\begin{array}{l}\text { Kurang } \\
\text { (Siswa yang } \\
\text { mampu kurang } \\
\text { dari 50\%) }\end{array}$ \\
\hline $\begin{array}{l}\text { 2. Peu nyang } \\
\text { geukheun } \\
\text { deungon } \\
\text { disiplin? }\end{array}$ & $\sqrt{ }$ & $\mathrm{X}$ & $\begin{array}{ll}11 & \text { Siswa } \\
\text { Mampu; } & \\
4 \text { Siswa } & \text { Tidak } \\
\text { Mampu } & \end{array}$ & $\begin{array}{l}\text { Mampu } \\
\text { (Siswa yang } \\
\text { mampu Lebih } \\
\text { dari 50\% })\end{array}$ \\
\hline $\begin{array}{lr}3 . & \text { Pakon } \\
\text { mantong na } \\
\text { ureueng nyang } \\
\text { geulangga } \\
\text { disiplin? }\end{array}$ & $\sqrt{ }$ & $X$ & $\begin{array}{ll}11 & \text { Siswa } \\
\text { Mampu; } & \\
4 \text { Siswa } & \text { Tidak } \\
\text { Mampu } & \end{array}$ & $\begin{array}{l}\text { Mampu } \\
(\text { Siswa yang } \\
\text { mampu Lebih } \\
\text { dari 50\% })\end{array}$ \\
\hline $\begin{array}{l}4 . \quad \text { Peue } \\
\text { keundalajih } \\
\text { dalam }\end{array}$ & $\sqrt{ }$ & $X$ & $\begin{array}{ll}11 & \text { Siswa } \\
\text { Mampu; } & \end{array}$ & Mampu \\
\hline
\end{tabular}


Bania A.S, Imran : Analisis Kemampuan Literasi Membaca Siswa Sekolah Dasar Kota Langsa

\begin{tabular}{|l|l|l|l|l|}
\hline $\begin{array}{l}\text { tapeukong } \\
\text { disiplin? }\end{array}$ & & $\begin{array}{l}4 \text { Siswa Tidak } \\
\text { Mampu }\end{array}$ & $\begin{array}{l}\text { Siswa yang } \\
\text { mampu Lebih } \\
\text { dari 50\% ) }\end{array}$ \\
\hline $\begin{array}{l}5 . \quad \text { Pakiban } \\
\text { peundapat gata } \\
\text { keu ureung } \\
\text { nyang kayem } \\
\text { geulangga } \\
\text { disiplin? }\end{array}$ & & $\sqrt{ }$ & $\begin{array}{l}7 \text { Siswa } \\
\text { Mampu; } \\
8 \text { Siswa Tidak } \\
\text { Mampu }\end{array}$ & $\begin{array}{l}\text { (Siswa yang } \\
\text { mampu kurang } \\
\text { dari 50\% })\end{array}$ \\
\hline
\end{tabular}

\section{KESIMPULAN}

Hasil dari penelitian dapat dinyatakan bahwa kemampuan literasi membaca teks berbahasa Aceh pada siswa SD Negeri 10 di Kota Langsa adalah mampu/baik karena dari 5 soal yang diberi test menampilkan 3 soal dijawab dengan mampu (>50\%) dan 2 soal dijawab dengan kurang baik (31-50\%). Siswa lebih memahami teks soal yang mengandung jawaban tersurat didalam teks bacaan berbahasa Aceh yang berupa dialog dibandingkan teks soal yang menginginkan jawaban dengan nalar/opini atau jawaban tersirat di dalam dialog.

\section{DAFTAR PUSTAKA}

Agustin, S. dan Cahyono, B.E.H. 2017. Gerakan Literasi Sekolah Untuk Meningkatkan Budaya Baca di SMA Negeri 1 Geger. Jurnal Linguista. 1 (2): 55-62.

Frankel, Katherine K., Becker, Bryce L.C, Rowe, Marjorie W. dan Pearson, P. David. 2016. From "Whast is reading?" to What is literacy?. Journal of Education; Becoming a Nation of Reader: Retrospectives and Visions. 196 (3): 7-17.

Hanum, N. 2018. Analisis Kemiskinan dan Ketimpangan Distribusi Pendapatan di Kota Langsa; Studi kasus Gampong Matang Seulimeng. Jurnal Samudra Ekonomika, Vol. 2, No.2.

Hapsari, W., Ruhaena, L. dan Pratisti, W. D. 2017. Peningkatan Kemampuan Literasi Awal Anak Prasekolah Melalui Program Stimulasi. Jurnal Psikologi. 44 (3): 177-184.

Ibda, H. 2017. Urgensi Pemertahanan Bahasa Ibu di Sekolah Dasar. Jurnal Shahih. 2 (2): 194-207.

Kasiyun, S. 2015. Upaya Meningkatkan Minat Baca Sebagai Sarana Untuk Mencerdaskan Bangsa. Jurnal Pena Indonesia. 1 (1): 79-95.

Muhammadi, Taufina dan Chandra. 2018. Literasi Membaca Untuk Memantapkan Nilai Sosial Siswa SD. Jurnal LITERA. 17 (2): 202:212.

Sari, N. 2018. Integrasi Agama dan Budaya Aceh dalam Pembentukan Etos Kewirausahaan; Studi Kasus HIPMI dan KPMI Kota Langsa. Jurnal UIN-SU: Kitabah. 2 (2): 226-245.

Schimdt, C. 2018. Ethnographic Research on Children's Literacy Practices: Children's Literacy Experiences and Possibilities for Representation. Journal Ethnograpy and Education. 14 (4): 1-16.

Stebbing, D., Shelley, J., Warnes, M. and McMaster, C. 2019. What academics really think about information literacy. Journal of Information Literacy, 13(1), pp.21-44.

Steensel, R., Oostdam, R. dan Gelderen, A. 2019. Affirming and Undermining Motivations for Reading and Associations with Reading Comprehension, Age and Gender. Journal of Research and Reading. 00 (00): 1-17. ISSN 0141-0423. DOI:10.1111/14679817.12281. 
Bania A.S, Imran : Analisis Kemampuan Literasi Membaca Siswa Sekolah Dasar Kota Langsa

Whitten, C., Labby, S. dan Sullivan, S.L. 2016. The Impact of Pleasure Reading on Academic Success. The Journal of Multidisiplinary Graduate Research. 2 (4): 48-64.

Yati, D. 2015. Menyelamatkan Bahasa Daerah Melalui Pembelajaran Bahasa Yang Komunikatif. Proseding Seminar Nasional Bulan Bahasa UNIB. 157-170

\begin{tabular}{|l|l|l|l|}
\hline Accepted Date & Revised Date & Decided Date & Accepted to Publish \\
\hline 29 Juli 2020 & 03 Agustus 2020 & 08 Agustus 2020 & Ya \\
\hline
\end{tabular}

